\title{
TRANSUMBILICAL LAPAROSCOPIC CHOLECYSTECTOMY VERSUS STANDARD 4-PORT LAPAROSCOPIC CHOLECYSTECTOMY - RESULTS FROM PROSPECTIVE RANDOMIZED TRIAL AND 7 YEARS OF FOLLOW-UP
}

\author{
G. Ganchev*, A. Saroglu, A. Julianov \\ Department of Surgery, Trakia Hospital, Stara Zagora, Bulgaria
}

\begin{abstract}
PURPOSE: Laparoscopic cholecystectomy is a standard of care for patients with benign gallbladder disease. Recently single-incision techniques gained popularity in order to decrease surgical trauma and to improve cosmetic results and patient satisfaction. The aim of this study is to compare the results of our own modification of transumbilical cholecystectomy versus standard 4-port cholecystectomy in patients with uncomplicated gallstone disease.

METHODS: 80 patients (14 male, 66 female) at a mean age of 35 $\pm 2,5$ years (range 18-80) were randomly assigned to either standard 4-port cholecystectomy $(n=40)$ or transumbilical cholecystectomy $(n=40)$. Operative times, intraoperative complications, conversion rate, postoperative complications, pain, vomiting and cosmetic results were compared between two groups.

RESULTS: The total mean operative time in the SILC group was $43.63 \pm 7.49$ min., while in the SLC group it was $37.95 \pm 8.06 \mathrm{~min} .,(\mathrm{p}=0.002)$. Intraoperative complications and conversions were not recorded in this series. The mean postoperative pain assessed by VAS was: at 6th hour 3.35 (2-5) vs. 3.53 (2-6) $(\mathrm{p}=0.439)$, at 24th hour $2.58(1-4)$ vs. $2.2(1-5)(\mathrm{p}=0.04)$, at 48th hour $1.63(1-3)$ vs. $1.78(1-5)$ $(\mathrm{p}=0.544)$. The mean 10-point pain scores for SILC patients at 6 hours was 5.78 (3-9) vs. 6.33 (1-10) in SLC $(\mathrm{p}=0.161)$, at 24 hours $4.05(1-7)$ vs. $3.58(1-5)(\mathrm{p}=0.122)$, at 48 hour $2.83(1-5)$ vs. $2.4(1-5)$ $(\mathrm{p}=0.093)$. Postoperative vomiting was observed in $2(5 \%)$ of patients with SILC and $3(7.5 \%)$ of those with SLC by the end of the second hour after surgery. In the early postoperative period up to $72 \mathrm{~h}$, no complications were reported. In the late postoperative period up to 7 years $1(2.5 \%)$ operative wound surgery in the area of umbilical incision was reported in the SLC group and the presence of an umbilical hernia in $2(5 \%)$ of patients with SILC. Results of the cosmetic result evaluation at the end of the first month - Body Image Score - mean score of $10.35 \pm 1.48$ (min. 7, max. 12) for SILC and $10.38 \pm 1.41$ (min. 6, max. 13) for SLC ( $\mathrm{p}=0.776)$. Cosmetic score - mean of the sum of points $20 \pm 1,87$ (min.17max. 24) for SILC and 19.08 $\pm 2,1$ (min. 14-max. 23) for SLC ( $\mathrm{p}=0,577)$. On a scale of 1 to 10 , where 1 is "very ugly" and 10 is "almost imperceptible" (question N8), the mean for patients in the SILC group is $8.3 \pm 0.79$ (min. 7-max. 10) and at SLC $7.93 \pm 0.73$ (min. 6-max. 9) $(\mathrm{p}=0.125)$.

CONCLUSION: The results of this study demonstrated that both transumbilical cholecystectomy and standard 4-port cholecystectomy are equally safe and effective in the treatment of uncomplicated gallstone disease.
\end{abstract}

Key words: transumbilical laparoscopic cholecystectomy, standard laparoscopic cholecystectomy.

\section{INTRODUCTION}

More than 20 years ago, laparoscopic cholecystectomy (LC) replaced open cholecystectomy as a procedure of choice for the treatment of benign gallbladder diseases.

\footnotetext{
*Correspondence to: Galin Ganchev, Department of Surgery, Trakia Hospital, 6000 Stara Zagora, Bulgaria; e-mail: dr.ganchevsurg@gmail.com,tel.: 0899086667
}

The aim of this Randomised Controlled Trial (RCT) is to compare our own modified technique of SILC (1) versus the standard 4port laparoscopic cholecystectomy (SLC) with respect to the operative time, intraoperative complications, conversion rate, postoperative complications, pain, vomiting and cosmetic results. 


\section{PATIENTS AND METHODS:}

The criteria for inclusion in the study are: age over 18 years and the presence of uncomplicated gallstone disease, indicated for elective cholecystectomy.

Exclusion criteria: contraindications for general anesthesia, previous operations in the upper-right quadrant, pregnancy, clinical signs for acute cholecystitis.

\section{Patients}

The study includes 80 patients, aged 18 to 80 years (mean $35 \pm 2,5$ ). They were operated by the same team during the period 2012 to 2015 .
GANCHEV G., et al.

The patients were divided into two groups by randomization at the operating theatre, and were allocated to either standard LC or transumbilical LC. Closed envelopes method was used for the randomization of the patients.

\section{Randomization}

The admitted patients were randomized into 2 groups (SILC group and standard 4-port LC) using sealed opaque envelopes.

The randomization was performed just before surgery, after the induction of anesthesia. The flow chart of the study is presented at Figure 1.

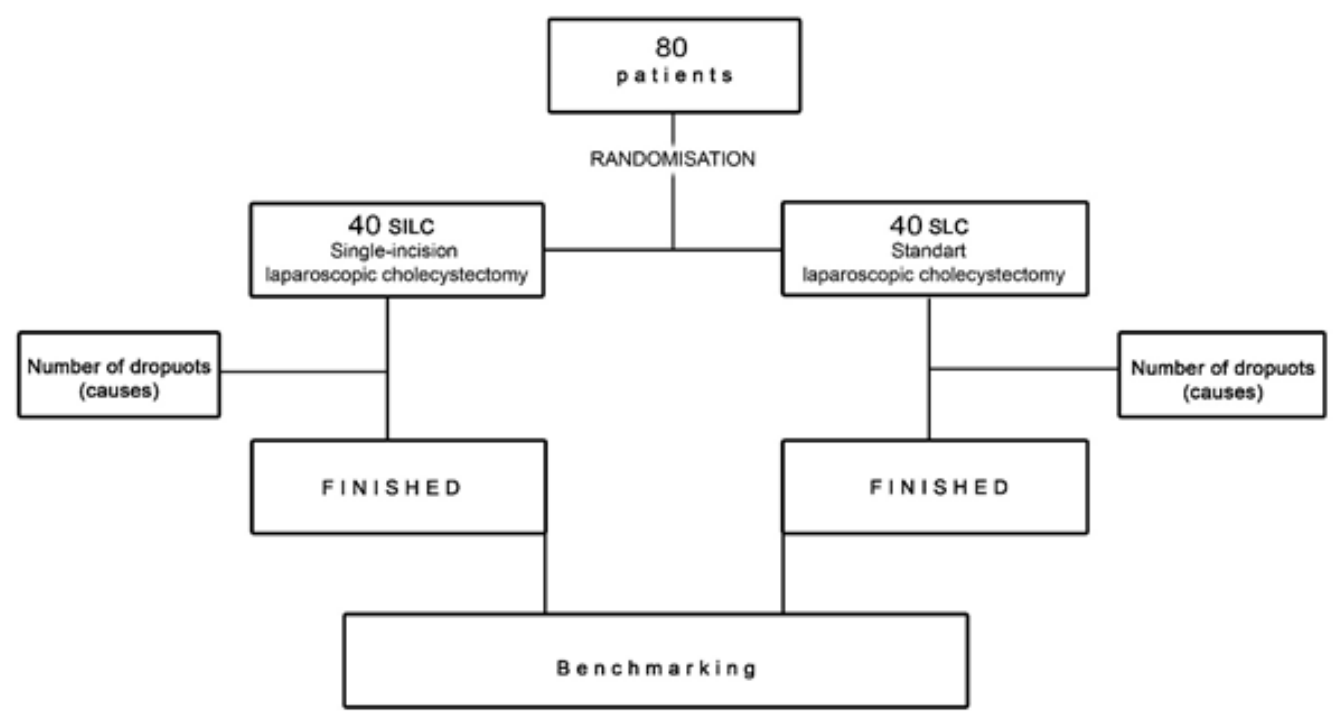

Figure 1. Randomisation of the patients.

\section{Preoperative evaluation of patients}

Preoperatively, all patients were examined for BCC, coagulation profile, biochemical studies to evaluate the functional status of the liver and kidney, chest radiography, abdominal ultrasound and ECG, consultation with a cardiologist, anesthesiologist and other specialists as needed.

\section{Position of the patient and the team}

All patients underwent general anesthesia in the supine position on the operating table with the legs folded. The position of the operator was to the left of the patient, and of the assistant and the operating nurse - to the right. The monitor was placed on the right side of the patient, at an angle comfortable for the operator and the entire team. In two monitors, one was on the right side of the patient-facing the operator and the other on the left side of the patient facing the assistant and the surgery nurse.

\section{Operative techniques}

Our SILC technique has been previously described elsewhere (1). In brief, we use a single continuous incision within the umbilical folds, 2 ports placed through the incision (one $10 \mathrm{~mm}$ and one $5 \mathrm{~mm}$ ) and a single $10-\mathrm{mm} 30^{\circ}$ camera. The concept of retracting sutures through the abdominal wall was applied to achieve a good exposure of the gallbladder and triangulation. We transfixed the infundibulum of the gallbladder with 2 or 3 bites in a figureof-eight fashion, with one end of the suture passed through the abdominal wall at the midline and the other at the anterior axillary line. This allows retracting the gallbladder in the desired lateral direction by maneuvering different ends of the suture, thus greatly facilitating the exposure. When necessary, more retracting sutures can be passed in a similar way. This technique helps overcoming difficulties in exposure when adhesions or inflammation are present. The other steps of 
the procedure are similar to the standard LC. In cases of large stones, we cut the fascial bridge between ports to remove the gallbladder and always close the fascia with sutures.

\section{Post-operative period and follow-up of patients:}

For all patients, the surgical post-operative period expired in a surgical department. Standard therapy in the first 24 hours includes $1000 \mathrm{ml} 10 \%$ glucose solution with $12 \mathrm{E}$ Insulin, $500 \mathrm{ml}$ Ringer, parenteral Dexketoprofen twice a dose of 50mg. i.v. and Pethidine hydrochloride twice a dose of $50 \mathrm{mg}$. In the presence of co-morbidity, the appropriate drug therapy is included.

Verticalization and feeding of the patients begin within the first 6-8 hours after surgery.

The follow-up of patients in both groups includes:

1. Early postoperative period - the following are reported:

1.1. The degree of pain on several visualanalogue scales at 6, 24 and 48 hours, respectively, and the needs for additional analgesia.
1.2. Passage recovery time - from the end of the operation until the first flatulation.

1.3. Post-operative nausea and vomiting - how many times and at what hour of surgery;

1.4. Postoperative complications;

1.5. The hospital stay.

\section{Statistical analysis}

For statistical analysis of the results, we used the SPSS program for Windows version 10.0 (SPSS, Chicago, IL, United States).

Descriptive statistics. Tests and graphs for normality of distribution.

Variational analysis. Student's t-test was used to compare groups of independent variables.

Alternative analysis. Test $\chi 2$ and Fisher test. These tests were used to assess intragroup and intergroup differences.

For all analyzes used, statistically significant differences were assumed at a significance level of $\mathrm{p}<0.05$ and a guarantee probability level of 0.95 .

\section{RESULTS}

Table 1. Destribution of the patients by Sex, BMI, Age, ASA

\begin{tabular}{|c|c|c|}
\hline & SILC & SLC \\
\hline Female / Male & $32(80 \%) / 8(20 \%)$ & $34(85 \%) / 6(15 \%)$ \\
\hline BMI & $27,2(20,8-37,5)$ & $29,8(19,2-41,1)$ \\
\hline Age & $53,64(18-80)$ & $57,26(20-79)$ \\
\hline ASA & $2(1-4)$ & $2(1-4)$ \\
\hline
\end{tabular}

The total mean operative time in the SILC group was $43.63 \pm 7.49$ min., while in the SLC group it was $37.95 \pm 8.06$ min., with a

Table 2. Operative times

\begin{tabular}{|l|c|c|c|}
\hline \multicolumn{1}{|c|}{ Total mean operative time } & SILC & SLC & p \\
\hline From skin incision to trocars / sutures placement & $43,63(32-72)$ & $37,95(25-56)$ & $\mathbf{p = 0 , 0 0 2}$ \\
\hline A. et d. cysticus transection & $6,85(3-15)$ & $6,3(2-12)$ & $P=0,307$ \\
\hline Gallbadder extraction & $16,03(5-34)$ & $13,5(6-25)$ & P=0,033 \\
\hline Ports closure & $13,3(5-25)$ & $11,2(4-24)$ & P=0,031 \\
\hline
\end{tabular}

In $7(17.5 \%)$ of the patients in the SILC group and in $9(22.5 \%)$ of the SLC group, intraoperative pericholecystic adhesions were found. Intra-abdominal adhesions throughout the upper right quadrant were observed in 2 (5\%) patients in the SLC group and in $1(2.5 \%)$ patient with SILC. statistically significant difference $(\mathrm{p}=0.002)$.

(Table 2)
No significant differences were found in the two groups according to the presence and severity of adhesions.

Intraoperative complications and conversions were not recorded in this series. 
An additional dose of analgesics was needed in the SILC group of $5(12.5 \%)$ patients versus 3 $(7.5 \%)$ in SLC.

Table 3. Pain

\begin{tabular}{|r|c|c|c|}
\hline \multicolumn{1}{|l|}{ VAS } & SILC & SLC & $\mathrm{p}$ \\
\hline $6 \mathrm{~h}$ & $3.35(2-5)$ & $3.53(2-6)$ & $\mathrm{P}=0,439$ \\
\hline $24 \mathrm{~h}$ & $2.58(1-4)$ & $2.2(1-5)$ & $\mathbf{P}=\mathbf{0 , 0 4}$ \\
\hline 48h & $1.63(1-3)$ & $1.78(1-5)$ & $\mathrm{P}=0,544$ \\
\hline point scale & & & $\mathrm{P}=0,161$ \\
\hline $6 \mathrm{~h}$ & $5.78(3-9)$ & $6.33(3-9)$ & $\mathrm{P}=0,122$ \\
\hline $24 \mathrm{~h}$ & $4.05(1-7)$ & $3.58(1-5)$ & $\mathbf{P}=\mathbf{0 , 0 9 3}$ \\
\hline
\end{tabular}

Postoperative vomiting was observed in $2(5 \%)$ of patients with SILC and $3(7.5 \%)$ of those with SLC by the end of the second hour after surgery.

Intestinal passage recovery occurred in patients in the SILC group on average 16.9 (7-24) hours after surgery and in the SLC group 17.3 (10-24) hours.

The average hospital stay in patients with SILC was 2.7 (1-5) days, with their subjective assessment of their condition ready for hospitalization on 2.1 (1-5) postoperative day.
In the SLC group, 3.2 (1-9) day and 2.4 (1-5) day, respectively.

In the early postoperative period, up to $72 \mathrm{~h}$., no complications were reported. In the late postoperative period, up to 7 years, $1(2.5 \%)$ operative wound surgery in the area of umbilical incision was reported in the SLC group and the presence of umbilical hernia in 2 $(5 \%)$ of the patients with SILC.

Results of the cosmetic result evaluation at the end of the first month:

Table 4. Cosmetic results

\begin{tabular}{|r|c|c|c|}
\hline & SILC & SLC & $\mathrm{p}$ \\
\hline Body Image Score & 10.35 & 10.38 & $\mathrm{p}=0.776$ \\
\hline Cosmetic Score & 20 & 19.08 & $\mathrm{p}=0,577$ \\
\hline 10 point scale & 8,3 & 7,93 & $\mathrm{p}=0.125$ \\
\hline
\end{tabular}

\section{DISCUSSION}

Similar to the results of other studies, operative time was longer in the SILC group compared to the SLC group (43.63 minutes versus 37.95 minutes). The mean operative time at SILC was 5.68 minutes longer than that for SLC, this making our results comparable to those of Aprea et al. $(41.03 \pm 12 / 35.6 \pm 5.6 \mathrm{~min}$.$) , and$ Tsimoyiannis et al. $(49.65 \pm 9 / 37.3 \pm 9.2$ min.)(14,15). SILC is slower in dissection in the Calot's triangle and in the dissection of the gallbladder from the gallbladder's bed compared to the SLC. Notwithstanding these results, it should be noted that the length of time that the SILC is longer is shorter of the SD for both operations, thus operating time cannot be regarded as an important factor in the choice of technique. The difficulties associated with SILC are mainly related to the parallel position of the trocars, causing space deficit, poor triangulation of the instruments, and the conflict at their proximal ends. The weak possibilities for triangulation between the instruments are successfully compensated by our modified method of gallbladder traction with two transparietal sutures. This allows the technique to be mastered relatively quickly by a team experienced in laparoscopic surgery and successfully applied to all candidates to laparoscopic cholecystectomy.

The advantage of our modification of the SILC technique is that it can performed with conventional laparoscopic instruments, which does not complicate the procedure. In contrast, most SILC techniques currently available use a variety of multichannel ports and specially designed instruments, which usually increases the cost of the procedure. On the other hand, our technique uses two trocars and two 
graspers less than SLC, which makes it more cost effective than standard (2).

No significant differences were found in the two groups according to the presence and severity of adhesions. Intraoperative complications and conversions were not recorded in this series.

A number of studies show different results in respect of postoperative pain in SILC and SLC groups. Bresadola et al. reported that postoperative pain is significantly lower for the SILC group (3). Increased postoperative pain in the SILC group was reported by Philipp et al. (4). The results of this study show that VAS pain scores at 48 hours, where statistical significance was found. It is stronger at SILC compared to SLC. Similar results are shown by a study of Lirici MM at al., whichis probably due to the higher pressure on the tissues around the umbilical port and the greater tissue trauma in the area (5).

Like other studies, this also shows there is no statistically significant difference in the two groups in terms of postoperative nausea and vomiting, recovery of the intestinal passage, average hospital stay $(6,7)$.

Postoperative complications in laparoscopic cholecystectomy are divided into surgical and non-surgical. The surgical ones can be divided into complications obtained in the early or late postoperative period. Most often these are:

1. Wound complications - bleeding, supra surgery, scar necrosis;

2. Intra-abdominal hemorrhage;

3. Biliragia;

4. Residual choledocholithiasis;

5. Biliary strictures;

6. Postoperative hernia.

A meta-analysis of Milas et al. ncluding 30 randomized controlled trials (SILC N $=1209$, MLC $N=1202$ ) reported a rate of postoperative complications of $5.35 \%$ in the SILC group, versus $3.79 \%$ in SLC (8). A similar study by Garg et al. reported an overall incidence of postoperative complications of $16 \%$ for SILC and $12.3 \%$ for SLC (9). Both meta-analyzes lack a statistically significant difference between the two methods. In our study, the overall incidence of postoperative complications was $5 \%$ for SILC and $2.5 \%$ for SLC. According to the literature, the highest incidence is complications of the wound. A meta-analysis by Garg et al. indicated $4.6 \%$
GANCHEV G., et al.

wound complications with SILC and $2.6 \%$ with SLC, with no statistically significant difference for the two methods (9). In the same study, the incidence of post-operative hernias at the incision site was reported to be $1.43 \%$ with SILC and $0.32 \%$ SLC, also with no statistically significant difference. Pisanu et al. reported for incisional hernia $1.3 \%$ in SILC vs. $0.2 \%$ in SLC, again statistically insignificant (10). In our study, we had one superophylaxis in the area of the umbilical incision $(2.5 \%)$ in a patient in the SLC group and two (5\%) postoperative hernias in the SILC group over a 6-month period onaverage.

Marks et al. in randomized controlled trials comparing SILC with SLC showed that SILC is superior to SLC in terms of cosmetic outcomes (11). Using a ten-point scale, 3 weeks postoperatively, $\mathrm{Ma}$ et al. reported a 9.3 score in the SILC group vs. 8.9 in the SLC group (12). In our series, when performing a correlation analysis with respect to the sex distribution, all three cosmetic test did not show statistically significant differences.

When dividing the SILC and SLC group by performing the BIS, CS, 1-10 tests, we found that in the first group in the 1-10 test, $62.5 \%$ of men identified their cicatrix as very good, while this percentage in women was $90,6 \%$ $(\mathrm{x} 2=3.97 ; \mathrm{p}=0.046)$. Using the other two tests, there is such a trend, but with no statistically significant difference. There is no statistically significant difference between patients in the SILC group and those with SLC in terms of the cosmetic effect after surgery.

\section{CONCLUSION}

Both procedures are comparable with respect to intraoperative difficulties and complications, postoperative nausea and vomiting, time to recover from the bowel passage, hospital stay, postoperative complications and cosmetic effect.

The data in the literature on cosmetic effects are quite contradictory. Given the lack of statistically significant difference between the two methodologies in our study, the cosmetic effect should be a factor for the patient's choice of methodology.

\section{REFERENCES}

1. Julianov, A. and Karashmalakov, A., Transumbilical laparoscopic cholecystectomy. Arch Surg, 145:402, 2010 
2. Qu JW, Xin C, Wang GY, Yuan ZQ, Li KW. Feasibility and safety of singleincision laparoscopic cholecystectomy versus conventional laparoscopic cholecystectomy in an ambulatory setting. Hepatobiliary Pancreat Dis Int. 2019 Jun;18(3):273-277.

doi: 10.1016/j.hbpd.2019.04.008. Epub 2019 Apr 23. PubMed PMID: 31056482.

3. Bresadola F., Pasqualucci A., Donini A., Chiarandini P., Anania G., Terrosu G. Elective transumbilical compared with standard laparoscopic cholecystectomy. Eur. J. Surg. 1999;165:29-34.

4. Philipp S.R., Miedema B.W., Thaler K. Single-incision laparoscopic cholecystectomy using conventional instruments: early experience in comparison with the gold standard. J. Am. Coll. Surg. 2009;209(5):632-637.

5. Lirici MM, Califano AD, Angelini $P$, Corcione F. Laparo-endoscopic single site cholecystectomy versus standard laparoscopic cholecystectomy: results of a pilot randomized trial. Am J Surg. 2011 Jul;202(1):45-52. doi: 10.1016/j.amjsurg.2010.06.019. Epub 2011 May 19. PubMed PMID: 21600559.

6. Cao Z.G., Cai W., Qin M.F., Zhao H.Z., Yue P., Li Y. Randomized clinical trial of single-incision versus conventional laparoscopic cholecystectomy: short-term operative outcomes. Surg. Laparosc. Endosc. Percutaneous Tech. 2011;21(5):311-313.

7. Lirici M.M., Califano A.D., Angelini P., Corcione F. Laparoendoscopic single site cholecystectomy versus standard laparoscopic cholecystectomy: results of a pilot randomized trial. Am. J. Surg. 2011;202:45-52.

8. Milas M, Deveđija S, Trkulja V. Single incision versus standard multiport
GANCHEV G., et al.

laparoscopic cholecystectomy: up-dated systematic review and meta-analysis of randomized trials. Surgeon. 2014 Oct;12(5):271-89.

doi:10.1016/j.surge.2014.01.009. Epub 2014 Feb 12. Review. PubMed PMID: 24529791.

9. Garg P, Thakur JD, Garg M, Menon GR. Single-incision laparoscopic cholecystectomy vs. conventional laparoscopic cholecystectomy: a metaanalysis of randomized controlled trials. $J$ Gastrointest Surg. 2012 Aug;16(8):161828. doi:10.1007/s1 1605-012-1906-6. Epub 2012 May 12. PubMed PMID: 22580841.

10.Pisanu A., Reccia I., Porceddu G., Uccheddu A. Meta-analysis of prospective randomized studies comparing singleincision laparoscopic cholecystectomy (SILC) and conventional multiport laparoscopic cholecystectomy (CMLC) $J$. Gastrointest. Surg. 2012;16:1790-1801.

11.Marks J.M., Phillips M.S., Tacchino R., Roberts K., Onders R., Denoto G. Singleincision laparoscopic cholecystectomy is associated with improved cosmesis scoring at the cost of significantly higher hernia rates: 1-year results of a prospective randomized, multicenter, single-blinded trial of traditional multiport laparoscopic cholecystectomy vs single-incision laparoscopic cholecystectomy. J. Am. Coll. Surg. 2013;216:1037-1047.

12.Ma J., Cassera M.A., Spaun G.O., Hammill C.W., Hansen P.D., Aliabadi-Wahle S. Randomized controlled trial comparing single-port laparoscopic cholecystectomy and four-port laparoscopic cholecystectomy. Ann.Surg. 2011;254(1):22 -27 . 